See discussions, stats, and author profiles for this publication at: https://www.researchgate.net/publication/324353440

\title{
Foraging behavior of juvenile loggerhead sea turtles in the open ocean: from Lévy exploration to area-restricted search
}

Article in Marine Ecology Progress Series · May 2018

Dol: 10.3354/meps 12581

\section{CITATIONS}

10

4 authors:

Freitas Carla

Institute of Marine Research in Norway

34 PUBLICATIONS 736 CITATIONS

SEE PROFILE

Jesus Reis

Oceanic Observatory of Madeira

7 PUBLICATIONS 30 CITATIONS

SEE PROFILE

Some of the authors of this publication are also working on these related projects:

RAIA View project

Project BEFISH View project
418

Rui M A Caldeira

ARDITI - Agência Regional para o Desenvolvimento da Investigação Tecnologia e I... 69 PUBLICATIONS 710 CITATIONS

SEE PROFILE

Thomas Dellinger

Universidade da Madeira

37 PUBLICATIONS 1,096 CITATIONS

SEE PROFILE 


\title{
Foraging behavior of juvenile loggerhead sea turtles in the open ocean: from Lévy exploration to area-restricted search
}

\author{
Carla Freitas ${ }^{1,2, *}$, Rui Caldeira ${ }^{1}$, Jesus Reis ${ }^{1}$, Thomas Dellinger $^{3,4}$ \\ ${ }^{1}$ Oceanic Observatory of Madeira, Agência Regional para o Desenvolvimento da Investigação Tecnologia e Inovação, \\ 9020-105 Funchal, Madeira, Portugal \\ ${ }^{2}$ MARE - Marine and Environmental Sciences Center, 9020 - 105 Funchal, Madeira, Portugal \\ ${ }^{3}$ Laboratório de Biologia Marinha e Oceanografia, Universidade da Madeira, 9000-107 Funchal-Madeira, Portugal \\ ${ }^{4}$ CIBIO, Centro de Investigação em Biodiversidade e Recursos Genéticos, 4485-661 Vairão, Portugal
}

\begin{abstract}
Most sea turtle species spend part of, or their entire juvenile stage in pelagic habitats. A key question is how pelagic turtles exploit their environment to optimize prey intake and maximize fitness. This study combined animal telemetry with remote-sensed environmental data to quantify the drivers and patterns of foraging behavior of juvenile loggerhead sea turtles in the pelagic eastern North Atlantic. Juveniles ranged in size from 34 to $58 \mathrm{~cm}$ straight carapace length. First-passage time (FPT) analysis, used to quantify search effort, indicated that turtles performed area-restricted searches at nested spatial scales of 10 and 50 to $200 \mathrm{~km}$. High-usage areas, as quantified by FPT, were associated with increased dive activity and weak surface currents, as well as with oceanographic features (high chlorophyll $a$ and shallower bathymetry) thought to stimulate prey availability. Conversely, low-usage areas (i.e. transit areas) were associated with deep, probably exploratory dives, typical from Lévy movement patterns. Further interpretation of dive data indicates greater dive activity in shallow depths (0 to $10 \mathrm{~m})$ during the night and during transit. Conversely, greater activity at intermediate depths (10 to $50 \mathrm{~m}$ ) was observed during daytime, under strong lunar illumination and in high-usage areas, suggesting these depths are major daytime foraging layers. This study clarifies the foraging ecology of sea turtles during their development phase in the open sea, providing evidence that these pelagic predators can adjust their foraging strategies and effort in response to the local conditions of their dynamic environment.
\end{abstract}

KEY WORDS: Argos · Biologging $\cdot$ Caretta caretta $\cdot$ Dive histograms $\cdot$ Satellite telemetry

\section{INTRODUCTION}

Many marine top predators, including sea turtles, are in decline globally due to direct exploitation, bycatch and other indirect anthropogenic threats (e.g. Worm \& Tittensor 2011). Top predators can provide top-down control of food webs, and when these species are removed or displaced, resulting trophic cascades can alter the stability of marine ecosystems (Myers et al. 2007, Estes et al. 2011, 2016). For effec- tive mitigation of the direct and indirect threats facing these species, there is an acute need to understand their movements and behavioral ecology.

Most sea turtle species spend part of, or their entire development stage in pelagic habitats (Bolten 2003). A key question is how pelagic turtles exploit their environment to optimize prey intake and maximize fitness. The pelagic habitat is generally oligotrophic, with food resources often patchily distributed in space and time (Fauchald 1999). It is generally assumed that 
foraging animals should spend more time in areas where resources are relatively plentiful (Fauchald \& Tveraa 2003). Accordingly, individuals are expected to adjust their travelling behavior in response to prey density and maximize their prey encounters by increasing turning rates and reducing travel speed. This adaptive response to prey is generally referred to as area-restricted search (ARS) behavior (Kareiva \& Odell 1987). However, ARS trajectories may not always directly reflect foraging effort, as these may be biased by non-foraging activities such as resting or reproduction (Sommerfeld et al. 2013, Bestley et al. 2015). For aquatic species, diving patterns may provide added valuable information on foraging effort and strategies. It has been documented, for example, that diverse marine predators such as fish, jellyfish and sea turtles may show diving patterns that are mathematically described as Lévy flights (Sims et al. 2008, Humphries et al. 2010, Hays et al. 2012). Lévy flights are characterized by a pattern of short movement steps, interspersed with a few much longer relocation steps. Optimal search theory predicts that Lévy search strategies optimize prey encounters in areas where prey is sparse and distributed unpredictably (Bartumeus et al. 2002). Conversely, when prey are more uniformly distributed it is expected that Brownian (random) movement may optimize prey encounter rates (Bartumeus et al. 2002). Understanding the link between horizontal movement patterns, such as ARS behavior, and vertical movement patterns is a priority for a better understanding of the foraging ecology of marine predators in their 3-dimensional environment (Carter et al. 2016).

Loggerhead sea turtles Caretta caretta nest on tropical and temperate coastal beaches. Soon after hatching, juveniles enter the ocean and swim offshore, transiting to pelagic habitats (Carr 1987, Bolten 2003, Mansfield \& Putman 2013, Scott et al. 2014). They can remain in the oceanic realm for years to decades, moving back to coastal neritic waters as large juveniles (Bjorndal et al. 2003, Bolten 2003, Cardona et al. 2009, Mansfield et al. 2009). Recruitment to neritic habitat starts when juveniles are around 45 to $65 \mathrm{~cm}$ straight carapace length (SCL) (Mansfield \& Putman 2013). However, a number of studies indicate that there is a plasticity in habitat selection among larger juveniles, with many returning to offshore habitats (McClellan \& Read 2007, Mansfield et al. 2009, Mansfield \& Putman 2013). Advances in telemetric methods have provided valuable information on movements and behavior of juvenile loggerhead turtles during the pelagic stage, from neonates and young juveniles under $30 \mathrm{~cm}$ SCL (Mansfield et al. 2014, 2017, Scott et al. 2014) to larger juveniles in the 30 to $90 \mathrm{~cm}$ range (e.g. Polovina et al. 2000, 2003, 2004, Eckert et al. 2008, Kobayashi et al. 2008, McCarthy et al. 2010, Briscoe et al. 2016, Varo-Cruz et al. 2016, Cardona \& Hays 2018). There is evidence that pelagic juvenile loggerheads are often associated with eddies and other productive oceanographic features (e.g. Polovina et al. 2000, Mansfield et al. 2009, 2017, Gaube et al. 2017). Juveniles seem to undergo ontogenetic changes in diving behavior, from remaining mainly at the sea surface during their first year (Mansfield et al. 2014), to diving to depth once they are older (Polovina et al. 2003, Howell et al. 2010, Àlvarez de Quevedo et al. 2013, Mansfield \& Putman 2013, Varo-Cruz et al. 2016). Their foraging behavior, in particular the link between horizontal and vertical search strategies, is still not well understood.

In this study, we combined animal telemetry with remote-sensed environmental data to quantify the drivers and patterns of foraging behavior of juvenile loggerhead sea turtles (34 to $58 \mathrm{~cm}$ SCL) in the pelagic eastern North Atlantic. First-passage time (FPT) analysis was used to quantify horizontal search effort and ARS scales. By combining FPT with environmental and diving data, we tested how these pelagic turtles adjusted their foraging effort and strategies in response to the local conditions of their dynamic environment. Specifically, we tested the hypotheses that (1) foraging patterns and effort were linked to selected environmental features indicative of prey availability; (2) increased horizontal search effort, as quantified by FPT, was associated with either increased vertical search effort (dive activity) or increased resting bouts; and (3) the turtles' dive activity at specific depth layers, including the presence of Lévy diving patterns, was linked to horizontal search activity and was adjusted as a response to local conditions of their habitat.

\section{MATERIALS AND METHODS}

\section{Satellite telemetry}

A total of 10 loggerhead sea turtles were equipped with Argos satellite transmitters (Wildlife Computers SDR-T10; $360 \mathrm{~g}$ in air) at Madeira Island, Portugal, during spring and fall 1998 (see Fig. 1, Table 1). Turtles were caught while basking off the south coast of Madeira. Turtles were approached from behind by boat at slow speed and captured by hand (see Dellinger et al. 1997). Animals were brought into captivity for tagging and were released offshore 4 to $13 \mathrm{~d}$ 
later. Turtles ranged in size from 33.9 to $57.5 \mathrm{SCL}$ and weighed 7.5 to $29.5 \mathrm{~kg}$. Satellite transmitters were attached to the carapace using a 'backpack' attachment method adapted from (Balazs et al. 1996).

Satellite transmitters provided location and diving data (range 0 to $251 \mathrm{~m} ; 1 \mathrm{~m}$ resolution) via Service Argos. Data transmission limitations required diving data to be compressed into four $6 \mathrm{~h}$ histograms $\mathrm{d}^{-1}$ : night (21:00 to 03:00 $\mathrm{h}$ local time [GMT]), dawn (03:00 to 09:00 h), day (09:00 to $15: 00 \mathrm{~h}$ ) and dusk (15:00 to 21:00 h). Three types of histograms were obtained: the number of dives to maximum depth layers (maximum depth histograms), number of dives to dive duration categories (duration histograms) and the proportional time within each depth layer (timeat-depth histograms). See Fig. 2 for depth and duration bins defined for each type of histogram. While maximum depth and duration histograms provide the number of dives in each depth or duration bin, timeat-depth histograms provide a number between 0 and 255 for each depth bin. The proportion of time at each depth bin can be posteriorly estimated by dividing each bin value by the sum of all bins.

Location data obtained from Argos were filtered using an algorithm based on speed of movement and turning angles (Freitas et al. 2008b). Filtering aimed to eliminate unlikely locations requiring unrealistic swimming speeds $\left(>2 \mathrm{~m} \mathrm{~s}^{-1}\right)$ and turning angles, and was performed using the library 'argosfilter' in R software (R Core Team 2015). Dive histogram locations (at 00:00, 06:00, 12:00 and 18:00 h for night, dawn, day and dusk histograms, respectively) were later estimated by linear interpolation of the filtered track.

\section{Environmental data}

The following physical variables were obtained for all filtered locations and dive-histogram locations: sea bottom depth (Depth), sea surface temperature (SST), wind speed (Wind), chlorophyll a concentration (Chl) and ocean surface current speed (Curr). Depth data were extracted from GEBCO 2014 grid data, with 30" resolution. SST and Wind data were extracted from climate reanalysis data (ERA-Interim) from the European Center for Medium-Range Weather Forecasts (ECMWF), with daily time resolution and $14 \mathrm{~km}$ $\left(0.125^{\circ}\right)$ horizontal resolution. Chl a was obtained from weekly, $9 \mathrm{~km}\left(0.08^{\circ}\right)$ resolution satellite measurements from Sea-viewing Wide Field-of-view Sensor (SeaWiFS) of the National Aeronautics and Space Administration (NASA). Ocean surface current speed was extracted from daily, $0.33^{\circ}$ horizontal resolution data from NASA's Ocean Surface Current Analysis Real-time (OSCAR).

\section{FPT analysis}

FPT was used in this study to (1) obtain a measure of the time sea turtles spent in different sections of their track and (2) investigate the spatial scales of ARS. FPT is defined as the time required for a tracked animal to cross a circle of a given radius (Fauchald \& Tveraa 2003). In order to calculate FPT, we generated a location each $10 \mathrm{~km}$ by linear interpolation of the filtered track, and calculated the FPT at these locations for radii ranging from 5 to $300 \mathrm{~km}$ by $5 \mathrm{~km}$ increments using the R library 'adehabitatLT' (Calenge 2006). The variances of the log-transformed FPTs were then plotted for each individual in order to identify the radius of maximum variance (see Fig. S1 in the Supplement at www.int-res.com/articles/suppl/m595 p203_supp.pdf). This radius corresponds to the spatial scale at which the animal concentrated its time, i.e. the size of the ARS zones (Fauchald \& Tveraa 2003, 2006). Because habitat selection is often a hierarchical process (Johnson 1980), nested spatial scales may occur. In our study, most animals used a ARS scale of approximately $10 \mathrm{~km}$ (Fig. S1), where they spent a few hours to days ( $1.5 \mathrm{~h}$ to $13 \mathrm{~d})$ nested within a broader ARS scale ranging from 50 to $200 \mathrm{~km}$ (Fig. S1), where animals spent several hours to months (50 km: 0.4 to $41 \mathrm{~d}_{i} 100 \mathrm{~km}$ : 2 to $102 \mathrm{~d} ; 200 \mathrm{~km}$ : 6 to $162 \mathrm{~d}$ ). Note that 4 hierarchical orders of selection may be considered when studying habitat selection (Johnson 1980, Senft et al. 1987). FPT at the finer spatial scale in our study (10 $\mathrm{km}$ radius) quantifies habitat use at Johnson's third-order of selection (within-homerange selection), while FPT at the broader spatial scale (50 to $200 \mathrm{~km}$ radius) likely quantifies selection at the second-order selection (home range selection within the geographic range of the population).

In order to investigate the relationship between horizontal and vertical movements, FPTs (at the smallest ARS scale, i.e. $10 \mathrm{~km}$ ) were calculated for dive histogram locations. This scale was chosen as its temporal scale suited dive histogram duration (6 h). Further, habitat selection at this scale (within-homerange scale) is expected to be linked to the animal's daily foraging and resting rhythms, which are of interest here, in contrast to selection of home ranges at broader scales, which is often linked to dispersal processes or seasonal migrations (Morris 1987).

Cox proportional hazards $(\mathrm{CPH})$ models were used to investigate the relationship between search effort 
(i.e. FPT) and oceanographic conditions, following Freitas et al. (2008a). CPH models the time until an event occurs, in this case, time until a turtle leaves an area of radius $r$. Two $\mathrm{CPH}$ models were fitted, one using FPT at the smaller ARS spatial scale $(r=10 \mathrm{~km})$ and another at a broader ARS scale $(r=100 \mathrm{~km})$. Models took the following form:

$h_{i}(t)=\exp \left(\beta_{1} \operatorname{Depth}_{i}+\beta_{2} \operatorname{Chl}_{i}+\beta_{3} \operatorname{Curr}_{i}+a_{i}\right) h_{0}(t)$

where $h(t)$ is the hazard function for the $i^{\text {th }}$ individual (i.e. the risk that turtle $i$ will leave an area) at time $t$. Depth $_{i}$ is sea bottom depth, $\mathrm{Chl}_{i}$ is chl a concentration, and Curr $_{i}$ is ocean surface current speed at turtle i's location. $\beta_{1}$ to $\beta_{3}$ are the coefficients that describe the contribution of these explanatory variables. The term $a_{i}$ is the per-subject random effect, which is assumed to be normally distributed with mean 0 (see Pankratz et al. 2005), and $h_{0}(t)$ is the baseline hazard function at time $t$, i.e. the risk of leaving an area where all explanatory variables are equal to zero.

\section{Diving behavior analysis}

Time-at-depth histograms were used to investigate the proportion of time spent diving relative to horizontal search behavior (FPT $10 \mathrm{~km}$ radius). Turtles were considered to be diving when they were at depths $>1 \mathrm{~m}$, and at the surface when at 0 to $1 \mathrm{~m}$ depth. We hypothesized that turtles invested more time diving in areas where FPT was high. Alternatively, a negative relationship between time spent diving and FPT would indicate that ARS was related to increased resting time at the surface, rather than increased dive investment. Using a generalized linear mixed model (GLMM) with a binomial link, we modelled the proportion of time diving (i.e. proportion of time at depths $>1 \mathrm{~m}$ ) as a function of FPT. Turtle carapace length (i.e. SCL) was also entered as an explanatory variable to test eventual size-related differences in diving intensity. The model took the following form:

$$
\operatorname{Logit}\left(p_{i j}\right)=\alpha+\beta_{1} \mathrm{FPT}_{i j}+\beta_{2} \operatorname{Size}_{i}+a_{i j}+\varepsilon_{i j}
$$

The term $p_{i j}$ denotes the proportion of time spent diving by individual $i$ at the $6 \mathrm{~h}$ sampling period $j, \mathrm{FPT}_{i j}$ is FPT of individual $i$ at sampling period $j$ and Size $_{i}$ is the carapace size (SCL) of turtle $i$. The random intercept $a_{i j}$ allows for a random variation around the intercept $\alpha$, and is assumed to be normally distributed with mean 0 and variance $\delta^{2}$ individual. The term $\varepsilon_{i j}$ is independent normally distributed noise. Models were fitted using the R package 'Ime4', 'glmer' function. Because we used a vector of proportions as the response variable (total number of observations $>1 \mathrm{~m}$ depth / total number of observations), we set the total number of observations that led to each proportion using the weights argument in 'glmer'.

A further detailed analysis of the proportion of time spent diving at specific depth layers was performed using binomial GLMMs. We tested whether the proportion of time spent diving at layer $d$ was affected by time of the day, lunar illumination, turtle carapace size (SCL) or turtle's horizontal search intensity (FPT). We fitted one model for each of the following depth layers $(d): 1$ to 10,10 to 25,25 to 50 and $>50 \mathrm{~m}$. Models took the following form:

$$
\begin{aligned}
\operatorname{Logit}\left(p_{d i j}\right)= & \alpha+\beta_{1} \operatorname{Diel}_{j}+\beta_{2} \text { Moon }_{j}+\beta_{3} \text { Size }_{i} \\
& +\beta_{4} \mathrm{FPT}_{i j}+\alpha_{i j}+\varepsilon_{i j}
\end{aligned}
$$

The term $p_{d i j}$ denotes the proportion of time spent at depth layer $d$ by individual $i$ during the $6 \mathrm{~h}$ sampling period $j$, Diel $_{j}$ is the time of the day at sampling period $j$ and Moon $_{j}$ is moon illumination at period $j$. Size $_{i}$ is SCL of turtle $i$ and $\mathrm{FPT}_{i j}$ is FPT of individual $i$ at sampling period $j$.

Maximum depth histograms were subject to a quantitative analysis of the frequency of distribution of movement steps, in order to test whether the turtles' diving patterns followed a Lévy or Brownian motion probability. First, the total number of dives to each depth layer (i.e. move-step frequencies) were calculated for each turtle. Power law (Lévy) and exponential models were then fitted to log-transformed move-step frequency distribution data. Support of the power-law fit of the observed data would indicate that move-steps are best described by Lévy-like processes, whereas strong support of an exponential fit suggests that a Brownian (random) motion probability dominates (Sims et al. 2008, Humphries et al. 2010). To determine the relative support of the power-law model versus an exponential model, we fitted a linear model to $\log _{10} \mathrm{~N}(x) \sim \log _{10} x$ (power) and to $\log _{10} \mathrm{~N}(x) \sim$ $x$ (exponential), where $x$ represents depth bins (steplength bins) and $\mathrm{N}(x)$ are move-step frequencies, following Sims et al. (2008). Akaike's information criteria (AIC) weights were calculated for model comparisons, with the weight of any model varying from 0 (no support) to 1 (complete support) relative to the entire model set. Models were run for the entire track of each individual, using a linear model (' $\mathrm{lm}$ ' function in R). A model was also fitted to all individuals pooled, using a linear mixed model, with individual as random factor (R library 'Ime4', function 'Imer'). $\mathrm{R}^{2}$ values were calculated for model fit evaluation. For 
the mixed model, $\mathrm{R}^{2}$ was calculated as conditional $\mathrm{R}^{2}$, following Nakagawa \& Schielzeth (2013).

Lévy-like movements are characterized by a pattern of movement step lengths in which short movement steps are interspersed by a few much longer relocation steps. Optimal search theory predicts that predators should adopt search strategies known as Lévy flights where prey is sparse and distributed unpredictably, but that Brownian movement is sufficient for locating abundant prey (Bartumeus et al. 2002). We therefore hypothesized that extreme deep exploratory dives will be more likely in transit areas (where prey density is probably lower) and less frequent in ARS areas, where prey availability is probably more predictable. To test the hypothesis, maximum depth histogram data were used to model the probability of diving deeper than $d \mathrm{~m}$, as a function of movement, individual and temporal variables. The following binomial GLMM was used, using a vector of 0 (did not dive deeper than $d$ ) and 1 (dived deeper than $d$ ) in the response variable:

$$
\begin{aligned}
\operatorname{Logit}\left(p_{d i j}\right)= & \alpha+\beta_{1} \operatorname{Diel}_{j}+\beta_{2} \operatorname{Moon}_{j}+\beta_{3} \text { Size }_{i} \\
& +\beta_{4} \mathrm{FPT}_{i j}+a_{i j}+\varepsilon_{i j}
\end{aligned}
$$

where the term $p_{d i j}$ denotes the probability of diving deeper than $d \mathrm{~m}$ by individual $i$ during the $6 \mathrm{~h}$ sampling period $j$, Diel ${ }_{j}$ is the time of the day at sampling period $j$ and Moon $_{j}$ is moon illumination at period $j$. Size $_{i}$ is SCL of turtle $i$ and $\mathrm{FPT}_{i j}$ is FPT of individual $i$ at sampling period $j$.

Previous studies have associated extreme long dive durations in sea turtles with cold sea water conditions (Southwood et al. 2003, Hochscheid et al. 2005, 2007) or storm events (Sakamoto et al. 1990, Storch et al. 2006). Using dive duration histogram data, we modelled whether the probability of diving longer than $m$ min was affected by SST and wind speed. We also

Table 1. Tracking records of 10 juvenile loggerhead sea turtles tagged in Madeira in the spring and fall 1998. CCL: curved carapace length; SCL: straight carapace length

\begin{tabular}{|llllccccc|}
\hline $\begin{array}{l}\text { Turtle } \\
\text { ID }\end{array}$ & Name & $\begin{array}{l}\text { CCL } \\
\text { (cm) }\end{array}$ & $\begin{array}{c}\text { SCL } \\
(\mathrm{cm})\end{array}$ & $\begin{array}{c}\text { Released } \\
(1998)\end{array}$ & $\begin{array}{c}\text { No. days } \\
\text { tracked }\end{array}$ & $\begin{array}{c}\text { Average } \\
\text { bathimetry (m) }\end{array}$ & $\begin{array}{c}\text { Max dive } \\
\text { depth (m) }\end{array}$ \\
\hline $97-946$ & Lidia & 45.7 & 41.3 & 1 Apr & 274 & 3716 & $40-60$ \\
$97-947$ & Delia & 63.1 & 57.6 & $18 \mathrm{May}$ & 278 & 3908 & $60-80$ \\
$97-948$ & Magda & 50.5 & 46.1 & $18 \mathrm{May}$ & 109 & 3969 & $100-150$ \\
$97-949$ & Maria & 51.2 & 46.2 & 27 May & 342 & 2969 & $100-150$ \\
$97-950$ & Carla & 37.9 & 33.9 & 27 May & 158 & 3501 & $100-150$ \\
$98-291$ & Isabel & 57.7 & 52.3 & 10 Sep & 311 & 3769 & $>150$ \\
$98-292$ & Helena & 51.2 & 48.3 & 10 Sep & 341 & 2724 & $100-150$ \\
$98-293$ & Sofia & 48.6 & 44.5 & 10 Sep & 123 & 4110 & $80-100$ \\
$98-294$ & Tamia & 44.9 & 39.9 & 10 Sep & 57 & 4294 & $100-150$ \\
$98-295$ & Samina & 44.0 & 40.0 & 10 Sep & 280 & 2062 & $80-100$ \\
\hline
\end{tabular}

tested if there was an association between dive duration and FPT, as well as for eventual size-related differences in dive duration. The following binomial GLMM was used:

$$
\begin{aligned}
\operatorname{Logit}\left(p_{d i j}\right)= & \alpha+\beta_{1} \mathrm{SST}_{j}+\beta_{2} \operatorname{Wind}_{j}+\beta_{3} \operatorname{Size}_{i} \\
& +\beta_{4} \mathrm{FPT}_{i j}+\alpha_{i j}+\varepsilon_{i j}
\end{aligned}
$$

where $p_{\text {dij }}$ denotes the probability of diving longer than $m$ min by individual $i$ during the $6 \mathrm{~h}$ sampling period $j, \mathrm{SST}_{j}$ is sea surface temperature and $\mathrm{Wind}_{j}$ is wind speed at period $j$. Size $e_{i}$ is SCL of turtle $i$ and $\mathrm{FPT}_{i j}$ is FPT of individual $i$ at sampling period $j$.

Because model covariates used in this study were from widely different scales, all covariates were centered and scaled (centered to mean 0 and variance of 1), by subtracting the mean from each value and dividing by the sample standard deviation (function 'scale' in R). This standardization aimed to improve model computation and make comparison between model coefficients possible (Zuur et al. 2007).

\section{RESULTS}

\section{Horizontal movements}

Sea turtles were monitored for 57 to $342 \mathrm{~d}$ (mean = $227 \mathrm{~d}$; Table 1). Turtles travelled up to $2800 \mathrm{~km}$ away from their tagging site, and were found in waters ranging in depth up to $5644 \mathrm{~m}$ (average $3372 \mathrm{~m}$; Table 1, Fig. 1). Only a few locations (6\%) were in areas shallower than $1000 \mathrm{~m}$ (Fig. 1). During the study period, turtles used waters with SST between 14.3 and $25.4^{\circ} \mathrm{C}$ and chl a concentration between 0.05 and $0.28 \mathrm{mg} \mathrm{m}^{-3}$. Wind speed in those areas ranged between 0.2 and $22 \mathrm{~m} \mathrm{~s}^{-1}$. Ocean surface current speed was relatively low, ranging from 0.007 to $0.16 \mathrm{~m} \mathrm{~s}^{-1}$

FPT analysis indicated that most turtles performed ARS at a spatial scale of $10 \mathrm{~km}$, nested within broader ARS scales of 50 to $200 \mathrm{~km}$ (see Fig. S1 in the Supplement). At the broader spatial scale $(100 \mathrm{~km})$, turtles showed a significantly lower probability of leaving (i.e. spent more time in) areas of shallower bathymetry and high chl a concentration (Table 2, Fig. 1). Conversely, turtles spent less time in areas of higher current speed. At the finer spatial scale $(10 \mathrm{~km})$, turtles also spent more time in areas of decreased bathymetry and 

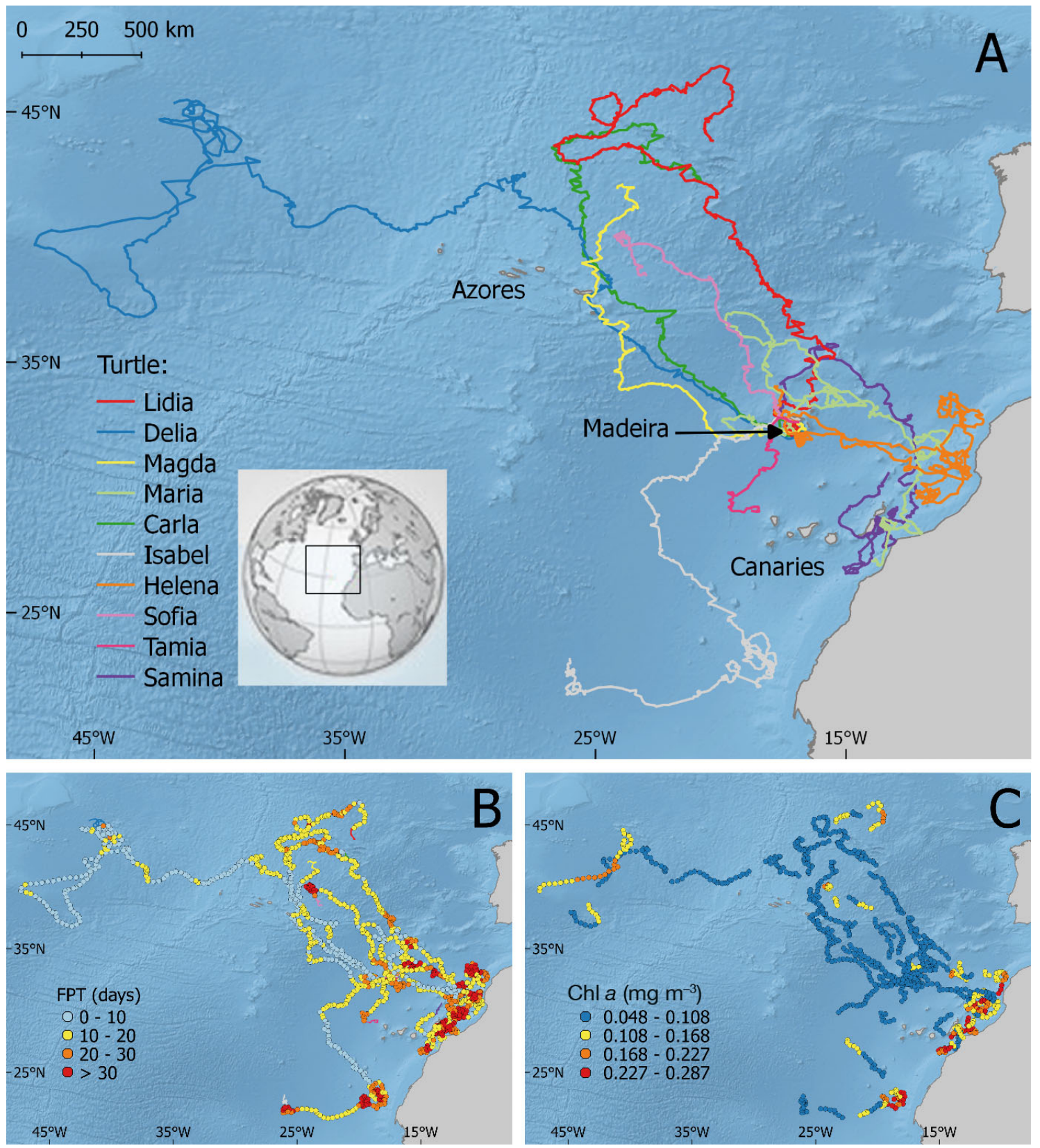

Fig. 1. Tracks of 10 loggerhead sea turtles tagged off Madeira colored by (A) turtle ID (see Table 1), (B) first-passage time (FPT) at $100 \mathrm{~km}$ radius and $(\mathrm{C})$ weekly chl a concentration. For increased readability, locations in (B) and (C) are shown at $40 \mathrm{~km}$ intervals

weaker surface currents, but no significant association with chl a concentration was found (Table 2).

\section{Time spent at depth}

Turtles spent on average two-thirds of their time diving $(>1 \mathrm{~m})$ and one-third of their time at the surface (0 to $1 \mathrm{~m}_{i}$ Fig. 2A). The proportion of time spent diving increased with FPT, independent of turtle size
(Table 3), indicating that ARS was associated with increased diving activity, rather than increased resting at the surface.

Diving activity was concentrated in the first $50 \mathrm{~m}$ of the water column, with less than $5 \%$ of the time being spent in deeper waters (Fig. 2A). The proportion of time spent at different depths was significantly associated with diel and lunar patterns. The proportion of time spent in shallow depths (1 to $10 \mathrm{~m}$ ) was higher during the night, while the proportion of 
Table 2. Cox proportional hazard models, modelling the effect of oceanographic conditions (chl a concentration, depth and ocean surface current speed) on the probability of juvenile loggerhead sea turtles leaving a 10 and $100 \mathrm{~km}$ radius area. Note: A $\beta$ coefficient $>0\left(e^{\beta}>1\right)$ indicates an increased risk of leaving, while a $\beta<0$ $\left(e^{\beta}<1\right)$ is interpreted in the opposite way. FPT: first-passage time

\begin{tabular}{|lcccccr|}
\hline Response & Covariate & $\beta$ & $\operatorname{Exp}(\beta)$ & $\mathrm{SE}(\beta)$ & $Z$ & \multicolumn{1}{c|}{$\mathrm{p}$} \\
\hline FPT 10 km & Chl & 0.003 & 1.003 & 0.019 & 0.140 & 0.890 \\
& Depth & 0.130 & 1.139 & 0.021 & 6.150 & $<0.001$ \\
& Curr & 0.057 & 1.058 & 0.019 & 3.040 & 0.002 \\
FPT 100 km & Chl & -0.068 & 0.934 & 0.021 & -3.320 & 0.001 \\
& Depth & 0.444 & 1.559 & 0.023 & 19.380 & $<0.001$ \\
& Curr & 0.163 & 1.177 & 0.020 & 8.070 & $<0.001$ \\
\hline
\end{tabular}

time spent in deeper depths was higher during daytime and under strong lunar illumination (Table 4). A significant association was also found between diving patterns and horizontal movements. Turtles spent significantly more time diving in shallow depths (1 to $10 \mathrm{~m}$ ) or in deep areas (>50 m) when in transit, while spending more time in intermediate depths (10 to $50 \mathrm{~m}$ ) in ARS zones where FPT was high (Table 4). Turtle SCL did not have a significant effect on the proportion of time spent at any depth (Table 4). Detailed time-at-depth plots for each individual turtle are presented in Fig. S2 in the Supplement.

\section{Vertical movement steps}

Vertical movements of tracked sea turtles were characterized by many shallow dives ( 2 to $6 \mathrm{~m}$ ) and a few much deeper movement steps (Fig. 2B). Many of the tracked individuals, including turtles with $<40 \mathrm{~cm} \mathrm{SCL}$, showed the capacity to dive to at least $100 \mathrm{~m}$ depth (Table 1). The analysis of step-length frequency distribution showed support for the Power law (Lévy) model for most individuals and for all individuals pooled (see Table S1 in the Supplement). The calculated exponents $(\mu)$ for these individuals varied between 1.5 and 1.9, indicating specialized randomwalk movement patterns close to the theoretical optimum $(1<\mu \leq 3)$ (Bartumeus et al. 2002, Viswanathan et al. 2008). Exponential model best fit was supported for a single individual (Samina), indicating movements consistent with normal random walks that approximate Brownian motion.

GLMMs showed that the probability of performing large movement steps (>60 and $>80 \mathrm{~m}$ depth) decreased with FPT (see Table S2 in the Supplement), demonstrating that such deep dives were more frequent in transit areas than in ARS zones. Further, the
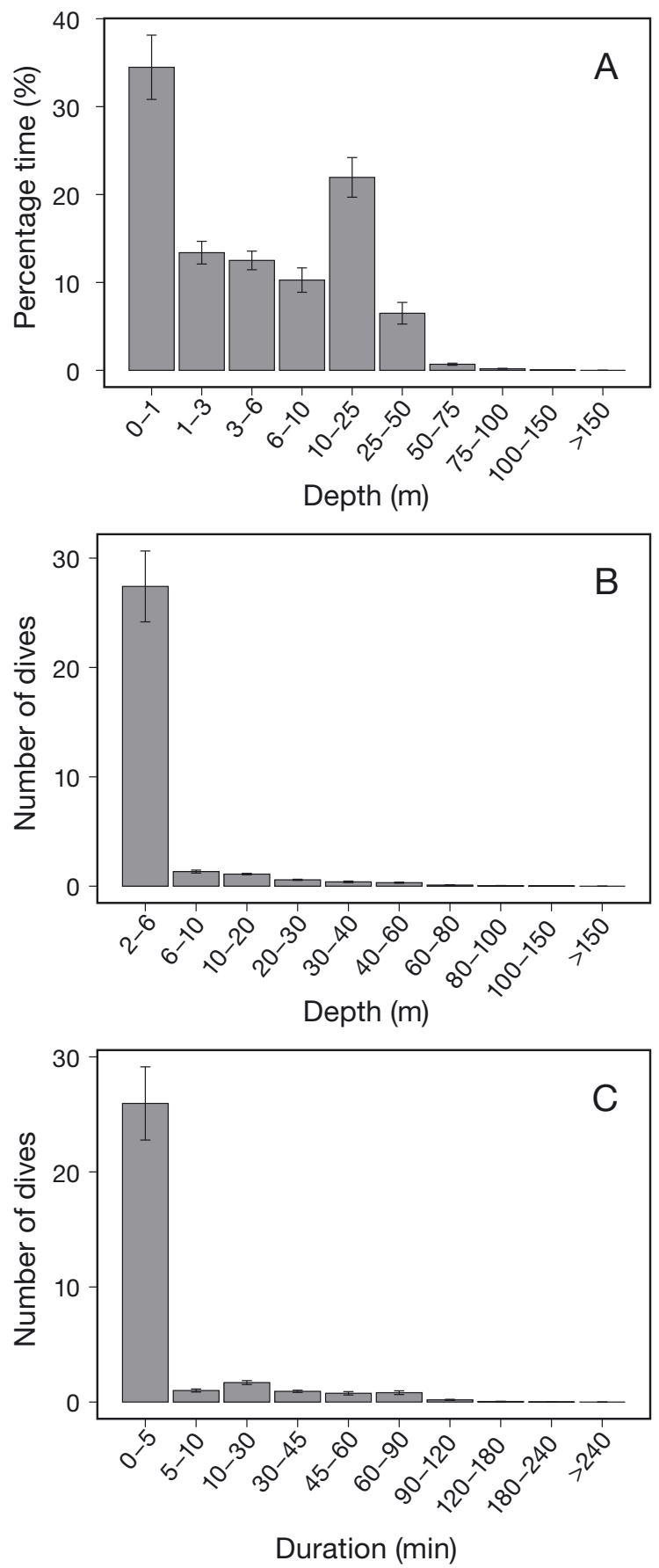

Fig. 2. Juvenile loggerhead sea turtles off Madeira showing (A) mean percentage time at depth, (B) mean number of dives (per $6 \mathrm{~h}$ period) as a function of maximum depth and (C) mean number of dives (per $6 \mathrm{~h}$ period) as a function of dive duration. Error bars: $\mathrm{SE}(\mathrm{n}=10$ ind.)

probability of performing such deep, probably exploratory dives was higher during daytime. No association with moon illumination or SCL was found (Table S2). 
Table 3. Estimated coefficients $(\beta)$ and corresponding standard errors (SE), $z$-values and significance levels (p), describing how the proportion of time juvenile loggerhead sea turtles spent diving ( $>1 \mathrm{~m}$ ) was affected by first-passage time (FPT) and turtle carapace size (Size)

\begin{tabular}{|lrrrr|}
\hline & $\beta$ & $\mathrm{SE}$ & \multicolumn{1}{c}{$z$} & \multicolumn{1}{c|}{$\mathrm{p}$} \\
\hline Intercept & 0.887 & 0.140 & 6.3 & $<0.001$ \\
FPT & 0.042 & 0.001 & 33.9 & $<0.001$ \\
Size & -0.078 & 0.139 & -0.6 & 0.576 \\
\hline
\end{tabular}

Table 4. Estimated coefficients $(\beta)$ and corresponding standard errors (SE), $z$-values and significance levels (p), describing how the proportion of time juvenile loggerhead sea turtles spent diving to specific depth layers was affected by time of the day (Diel), moon illumination (Moon), first-passage time (FPT) and turtle carapace size (Size)

\begin{tabular}{|c|c|c|c|c|c|}
\hline $\begin{array}{l}\text { Depth } \\
\text { (m) }\end{array}$ & $\begin{array}{l}\text { Model } \\
\text { component }\end{array}$ & $\beta$ & $\mathrm{SE}$ & $z$ & $\mathrm{p}$ \\
\hline \multirow[t]{7}{*}{$1-10$} & Intercept & 0.648 & 0.131 & 5.0 & $<0.001$ \\
\hline & Diel (dawn) & 0.285 & 0.004 & 73.5 & $<0.001$ \\
\hline & Diel (day) & -1.165 & 0.004 & -296.7 & $<0.001$ \\
\hline & Diel (dusk) & -0.849 & 0.004 & -233.9 & $<0.001$ \\
\hline & Moon & -0.017 & 0.001 & -12.8 & $<0.001$ \\
\hline & FPT & -0.011 & 0.001 & -8.0 & $<0.001$ \\
\hline & Size & -0.093 & 0.130 & -0.7 & 0.474 \\
\hline \multirow[t]{7}{*}{$10-25$} & Intercept & -0.909 & 0.094 & -9.6 & $<0.001$ \\
\hline & Diel (dawn) & -0.262 & 0.004 & -65.1 & $<0.001$ \\
\hline & Diel (day) & 0.534 & 0.004 & 136.2 & $<0.001$ \\
\hline & Diel (dusk) & 0.379 & 0.004 & 101.9 & $<0.001$ \\
\hline & Moon & -0.009 & 0.001 & -6.5 & $<0.001$ \\
\hline & FPT & 0.007 & 0.001 & 5.1 & $<0.001$ \\
\hline & Size & 0.019 & 0.094 & 0.2 & 0.837 \\
\hline \multirow[t]{7}{*}{$25-50$} & Intercept & -3.448 & 0.367 & -9.4 & $<0.001$ \\
\hline & Diel (dawn) & -0.090 & 0.009 & -9.5 & $<0.001$ \\
\hline & Diel (day) & 1.697 & 0.008 & 225.2 & $<0.001$ \\
\hline & Diel (dusk) & 1.477 & 0.007 & 198.4 & $<0.001$ \\
\hline & Moon & 0.053 & 0.002 & 24.0 & $<0.001$ \\
\hline & $\mathrm{FPT}$ & 0.030 & 0.002 & 13.9 & $<0.001$ \\
\hline & Size & 0.294 & 0.361 & 0.8 & 0.417 \\
\hline \multirow[t]{7}{*}{$>50$} & Intercept & -5.119 & 0.665 & -7.7 & $<0.001$ \\
\hline & Diel (dawn) & -0.572 & 0.019 & -29.6 & $<0.001$ \\
\hline & Diel (day) & 0.928 & 0.014 & 64.3 & $<0.001$ \\
\hline & Diel (dusk) & 0.651 & 0.014 & 45.4 & $<0.001$ \\
\hline & Moon & 0.077 & 0.005 & 15.6 & $<0.001$ \\
\hline & $\mathrm{FPT}$ & -0.088 & 0.005 & -16.5 & $<0.001$ \\
\hline & Size & 0.770 & 0.662 & 1.2 & 0.245 \\
\hline
\end{tabular}

\section{Dive duration}

Most dives performed by sea turtles were not only shallow, but also of short duration, lasting less than 5 min (Fig. 2C). However, turtles performed at least one dive lasting 10 to 90 min in most $6 \mathrm{~h}$ sampling periods (Figs. 2C \& S3 in the Supplement). Con- versely, dives lasting more than $2 \mathrm{~h}$ were rare (Figs. 2C \& S3). These occurred in association with lower SST conditions (Table S2). Curiously, dives lasting over $3 \mathrm{~h}$, in association with low SST, were relatively shallow ( $<30 \mathrm{~m}$ depth) and occurred in both coastal and offshore areas (42 to $3752 \mathrm{~m}$ sea bottom depth), during winter and spring (January to April; Table S3). Contrary to our hypothesis, prolonged dives (>120 min) were not associated with strong wind conditions (Table S2).

\section{DISCUSSION}

In this study, tracking and diving data were integrated to elucidate the foraging behavior of pelagic juvenile loggerhead turtles in the eastern North Atlantic. ARS behavior was detected at nested spatial scales, and high-usage areas (quantified by FPT) were associated with increased dive activity rather than larger resting activity at the surface. As expected, these areas of high horizontal and vertical search activity were associated with oceanographic features known to stimulate prey availability. Conversely, low-usage areas (i.e. transit areas) were associated with deep, likely exploratory dives, typical of Lévy movement patterns. Interpretation of dive data indicates greater dive activity in shallow waters ( 0 to $10 \mathrm{~m}$ ) during the night and during transit and conversely, greater activity in intermediate waters (10 to $50 \mathrm{~m}$ ) during daytime and in high-usage areas, suggesting the latter are major daytime foraging layers.

It is widely recognized that habitat selection and use are hierarchical processes, in which 4 orders of selection can be identified based on the spatial scale at which habitat selection is measured (Johnson 1980). First-order selection refers to selection of the physical or geographical range of a species; secondorder selection is selection of the home range of an individual or social group; third-order selection refers to selection of feeding or resting sites within a home range; and fourth-order selection refers to the actual food items, for example, from those available at that site (Johnson 1980). The temporal and geographical span of this study enabled us to identify 2 of these scales. At the second-order scale, individuals concentrated their time at broad ARS areas of 50 to $200 \mathrm{~km}$ radius. At this broad scale, high-usage areas were associated with increased chl a concentration, shallower bathymetry and weaker surface currents. At finer spatial scales (third-order selection), individuals concentrated their time at ARS areas of $10 \mathrm{~km}$, also associated with low bathymetry features and 
weaker currents, but not directly associated with chl a concentration. It is likely that different environmental features influence animal movements at different spatial scales. While these environmental parameters appear to correlate with turtle movements at the scales of 10 and 50 to $200 \mathrm{~km}$, other factors such as the Earth's magnetic field, SST and major ocean currents may play more of a role at larger spatial scales (Coles et al. 2000, Lohmann 2007, Putman et al. 2015, Cardona \& Hays 2018).

The positive relationship between time spent in an area and chl $a$ is likely due to increased prey availability in those areas. Similar associations have been observed in various pelagic areas (Polovina et al. 2000, 2004, Kobayashi et al. 2008, Mansfield et al. 2009, McCarthy et al. 2010, Barceló et al. 2013, Scales et al. 2015). No significant relationship with chl $a$ was detected at the finest scale $(10 \mathrm{~km})$, perhaps due to the spatial and temporal scale of chl a measurements (i.e. weekly, $9 \mathrm{~km}$ data). Note also that there is likely a time lag between a chl a bloom and when larger predators may benefit from that bloom. Therefore, chl a measurements may not necessarily correlate with animal movements at fine temporal scales. At both fine and broad ARS scales, habitat use intensity was associated with bathymetry, as animals spent significantly more time in the vicinity of shallower bathymetry areas. Such areas included offshore seamounts and the continental shelf break of Africa. Curiously, loggerhead sea turtles tagged in the Canary Islands also foraged largely in this area off the African coast (Varo-Cruz et al. 2016). Bathymetric features such as oceanic seamounts and continental shelf breaks are known to promote biodiversity (e.g. Morato et al. 2010, Christensen Dalsgaard et al. 2018). High-relief bathymetric areas function as natural obstacles to marine currents, dragging deep, nutrient-rich waters over the shallow bottom, which can result in increased marine productivity (White et al. 2008). Such bathymetric features may also generate mesoscale oceanographic features, such as eddies and meanders, which may affect juvenile loggerhead movements (Polovina et al. 2000, Mansfield et al. 2009, 2014, Gaube et al. 2017). High primary productivity and energetic physical features (eddies, meanders and fronts) that rouse and concentrate this productivity are likely to allow food webs to develop, resulting in high prey availability. Using the same tracks as in this study, McCarthy et al. (2010) analyzed the track sinuosity of the animals relative to oceanographic features. In addition to an association with bathymetry and $\mathrm{chl} a$, turtles showed more sinuous tracks in areas of lower SST. Further analysis of the oceanographic conditions experienced by the study animals, performed in this study, showed a negative correlation between chl $a$ and SST (i.e. areas of increased chl a were generally colder, possibly due to upwelling events). As we were interested in testing the effect of chl $a$ on habitat use at different spatial scales, SST was not included as covariate to avoid collinearity during model fit. Recent studies suggest that juvenile loggerhead movements can be affected both by ocean currents and by active movements (Mansfield et al. 2014, 2017, Scott et al. 2014, Putman \& Mansfield 2015, Briscoe et al. 2016, Putman et al. 2016, Cardona \& Hays 2018). This study provides evidence for both. Turtles spent less time in areas with stronger surface currents, indicating an effect of ocean currents on turtle movements. On the other hand, the relationship between turtle movements and oceanographic features such as bottom depth and chl a concentration suggests an active selection of productive habitat, rather than random use of the open ocean.

Turtles in this study exhibited a variety of migratory paths. Juvenile loggerheads found in the eastern North Atlantic, namely around the Azores, Madeira and Canary Islands, mainly originate from the western North Atlantic, with little genetic contributions from the Mediterranean, Cape Verde and South Atlantic rookeries (Bolten et al. 1998, Carreras et al. 2006, Monzón-Argüello et al. 2009, LaCasella et al. 2013). Some animals in this study travelled north, apparently against the prevailing currents, while others travelled south and west towards the African coast, overlapping with the main foraging areas of turtles tagged in the Canary Islands (Varo-Cruz et al. 2016). It is possible that differences in migratory paths could relate to differences in genetic origin (e.g. distinct western Atlantic origins), but no genetic origin data are available to test this hypothesis. Alternatively, it is possible that local oceanographic conditions, such as the presence of mesoscale features (Tew Kai et al. 2009), may have affected the movements of the tracked animals. A deeper analysis of turtle movements in relation to ocean currents is needed to test this hypothesis.

This study highlights the relationship between horizontal movement patterns and diving activity. Foraging behavior models based exclusively on horizontal movements may not directly translate into the vertical dimension in dynamic marine environments (Sommerfeld et al. 2013, Bestley et al. 2015). For sea turtles that may spend large amounts of time resting at the surface, diving information provides valuable information for interpreting foraging be- 
havior. Turtles in this study spent on average onethird of their time at the surface. However, as hypothesized, high-usage areas were associated with augmented dive activity rather than increased time at the surface, suggesting increased foraging effort in those areas. Conversely, transit areas with low FPT were associated with decreased dive activity, i.e. with increased time spent at the surface, probably as a result of decreased prey availability. Interestingly, adult leatherback turtles travelling in pelagic habitats also showed similar patterns, having increased dive activity during the foraging phase compared to the migratory phase (Shillinger et al. 2011).

Time spent at different depth layers was also associated with movement patterns. Though sea turtles were mostly located over deep oceanic areas (average bottom depth $>3000 \mathrm{~m}$ ), their diving activity there was much shallower, since over $95 \%$ of their diving time was spent in water depths less than $50 \mathrm{~m}$. Most dives were very shallow ( $<6 \mathrm{~m}$ depth) and of short duration ( $<5 \mathrm{~min})$. This pattern is similar to the behavior observed in juvenile loggerheads of similar size range tracked off the Canary Islands (Varo-Cruz et al. 2016) and other regions (Polovina et al. 2003, Howell et al. 2010, Àlvarez de Quevedo et al. 2013). The observations are also consistent with what is known about their feeding ecology. Pelagic loggerheads feed on a variety of pelagic cnidaria (e.g. Carinaria cithara, Velella velella), pelagic mollusca (e.g. Glaucus atlanticus, Janthina spp.), as well as on flotsam-associated barnacles and crabs (Parker et al. 2005, Frick et al. 2009). Some of these prey items are strictly associated with the surface, but some gelatinous zooplankton are known to perform diel vertical movements (e.g. Nogueira Júnior et al. 2015). Turtles in our study tended to dive deeper during the day and shallower at night. Similar patterns have been reported for larger juveniles in the Pacific (Polovina et al. 2003, 2004), as well as for adult loggerhead and leatherback turtles in pelagic areas (Shillinger et al. 2011, Scales et al. 2015). Diel and lunar patterns in dive activity, reported here, consisting of deeper dive activity during the day and under strong lunar illumination are likely to reflect diel vertical movements of their prey. The use of intermediate depth layers (10 to $50 \mathrm{~m}$ ) during daytime, particularly in ARS zones where FPT was high, indicate that these depth layers are major daytime foraging layers for pelagic loggerheads. It is possible that, in addition to prey availability, temperature in the water column affected the time spent by the study animals at different depths (see Mansfield 2006). Unfortunately, no temperatureat-depth data were available here to verify this possi- bility. Time spent at depth was independent of turtle body size. All turtles showed the capacity to dive to depth, including the smallest juveniles (34 to $40 \mathrm{~cm}$ SCL), which dived to at least $100 \mathrm{~m}$ depth. Diving data for juvenile loggerheads in the 30 to $40 \mathrm{~cm}$ range are rare (Varo-Cruz et al. 2016). It is generally assumed that loggerheads shift their diet once they recruit to nearshore habitats and become benthic foragers; however, perhaps an earlier shift in diet occurs at around $30 \mathrm{~cm}$ SCL (Mansfield \& Putman 2013). This study supports the hypothesis that juvenile loggerheads undergo ontogenetic changes in foraging behavior, from remaining exclusively at the surface during the first year (Mansfield et al. 2014) to diving to depth when they are over $30 \mathrm{~cm}$ SCL.

Most sea turtles in this study showed Lévy-like dive patterns. These consist of many shallow displacement steps, interceded by few much longer steps (dives), which in theory optimizes prey encounters in areas where prey availability is scarce and unpredictable (Bartumeus et al. 2002). Curiously, most deep, probably exploratory dives (deeper than $60 \mathrm{~m}$ ) were more likely to occur in transit areas compared to ARS zones, likely due to scarcer and more unpredictable prey availability. Again, adult leatherback turtles inhabiting pelagic areas also showed a similar behavior, performing seldom very deep dives (>800 m) during the migration phase (Shillinger et al. 2011). These observations support recent empirical evidence that Lévy movements are more likely to occur in areas of scarce prey availability (Humphries et al. 2010, Sims et al. 2012) and result in increased foraging success in such habitats (Humphries et al. 2012). Note, however, that Lévy patterns may not necessarily result from fundamental search strategies adopted by foraging animals. Perhaps Lévy-like movements result from environmental forcing or from complex search behavior based on sensory or memory-based information. Movement patterns requiring many turns, such as Lévy flights and ARS, incur additional energetic costs compared to more straight-line movements (Wilson et al. 2013). However, they are often observed in nature, suggesting that energetic gains compensate for the cost.

Temperature within the water column can affect the diving behavior of sea turtles, including dive duration (Mansfield 2006). The metabolic rates of sea turtles vary with water temperature, and as temperature decreases, dive capacity increases because of lowered use of stored oxygen (e.g. Hochscheid et al. 2005, Thomson et al. 2012). Because temperature-atdepth was not available in this study for a detailed analysis of diving duration relative to ambient tem- 
perature, SST was used instead as a proxy for ambient temperature. As expected, we found a negative relationship between dive duration and SST, i.e. turtles showed a larger probability to perform long dives (>120 min) when SST decreased. Turtles in this study used waters with surface temperatures down to $14.3^{\circ} \mathrm{C}$. It is unknown whether the turtles' body temperatures decreased this low, since sea turtles have some ability to thermoregulate by basking at the surface (Sapsford \& van der Riet 1979, Mansfield et al. 2014). It has been suggested in the past that water temperatures below $15^{\circ} \mathrm{C}$ provoke hibernation in sea turtles that become dormant on the sea floor and do not re-emerge for as long as the low water temperatures persist, even for months (Felger et al. 1976). Modern telemetry techniques have demonstrated that when sea temperature decreases, rather than hibernating, sea turtles may perform long aerobic dives which allow them to rest in a dormant state for hours and keep energetic costs at a minimum (Southwood et al. 2003, Hochscheid et al. 2005, 2007). This is probably the case of the prolonged dives observed in this study in association with significant decreased SST. Increased dive duration during storms has been observed in previous studies of sea turtles in coastal habitats (Sakamoto et al. 1990, Storch et al. 2006). Our study did not detect an association between dive duration and wind speed. We also tested whether the probability of performing prolonged dives was associated with FPT, but no relationship was found, suggesting that ARS patterns were not biased by prolonged resting dives.

This study discloses new aspects of the foraging behavior of juvenile loggerhead sea turtles in the open ocean, in particular the relationship between horizontal and vertical movement patterns and the effect of physical and circadian variables on their spatial movements and diving behavior. This information is valuable for a better understanding of the ecology of this species, namely the strategies used to fulfil their requirements for food and other vital needs. This information may also be crucial for implementing adequate conservation measures aimed at minimizing eventual interactions with fisheries and other anthropogenic activities.

Acknowledgements. This study was funded by a Life Nature project (Life96Nat/P/3019). C.F., R.C. and J.R. were financially supported by the Oceanic Observatory of Madeira Project (M1420-01-0145-FEDER-000001-Observatório Oceânico da Madeira-OOM). We thank Renato Barradas for field assistance and Alan B. Bolten for help with turtle tagging. We also thank Kate Mansfield and 2 anonymous reviewers for valuable comments that improved the manuscript.

\section{LITERATURE CITED}

Àlvarez de Quevedo I, San Félix M, Cardona L (2013) Mortality rates in by-caught loggerhead turtle Caretta caretta in the Mediterranean Sea and implications for the Atlantic populations. Mar Ecol Prog Ser 489:225-234

Balazs GH, Miya RK, Beavers SC (1996) Procedures to attach a satellite transmitter to the carapace of an adult green turtle, Chelonia mydas. NOAA technical memorandum NMFS-SEFSC-387. National Marine Fisheries Service, Miami, FL

Karceló C, Domingo A, Miller P, Ortega L and others (2013) High-use areas, seasonal movements and dive patterns of juvenile loggerhead sea turtles in the southwestern Atlantic Ocean. Mar Ecol Prog Ser 479:235-250

* Bartumeus F, Catalan J, Fulco UL, Lyra ML, Viswanathan GM (2002) Optimizing the encounter rate in biological interactions: Lévy versus Brownian strategies. Phys Rev Lett 88:097901

* Bestley S, Jonsen ID, Hindell MA, Harcourt RG, Gales NJ (2015) Taking animal tracking to new depths: synthesizing horizontal-vertical movement relationships for four marine predators. Ecology 96:417-427

* Bjorndal KA, Bolten AB, Dellinger T, Delgado C, Martins HR (2003) Compensatory growth in oceanic loggerhead sea turtles: response to a stochastic environment. Ecology 84: 1237-1249

Bolten AB (2003) Variation in sea turtle life history patterns: neritic vs. oceanic developmental stages. In: Lutz PL, Musick J, Wyneken J (eds) The biology of sea turtles, Vol 2. CRC Press, Boca Raton, FL, p 243-258

* Bolten AB, Bjorndal KA, Martins HR, Dellinger T, Biscoito MJ, Encalada SE, Bowen BW (1998) Transatlantic developmental migrations of loggerhead sea turtles demonstrated by mtDNA sequence analysis. Ecol Appl 8:1-7

Briscoe DK, Parker DM, Balazs GH, Kurita M and others (2016) Active dispersal in loggerhead sea turtles (Caretta caretta) during the 'lost years'. Proc R Soc B 283:20160690

Calenge C (2006) The package 'adehabitat' for the R software: a tool for the analysis of space and habitat use by animals. Ecol Modell 197:516-519

* Cardona L, Hays GC (2018) Ocean currents, individual movements and genetic structuring of populations. Mar Biol 165:10

* Cardona L, Revelles M, Parga ML, Tomás J and others (2009) Habitat use by loggerhead sea turtles Caretta caretta off the coast of eastern Spain results in a high vulnerability to neritic fishing gear. Mar Biol 156:2621-2630

Carr A (1987) New perspectives on the pelagic stage of sea turtle development. Conserv Biol 1:103-121

Carreras C, Pont S, Maffucci F, Pascual M and others (2006) Genetic structuring of immature loggerhead sea turtles (Caretta caretta) in the Mediterranean Sea reflects water circulation patterns. Mar Biol 149:1269-1279

* Carter MID, Bennett KA, Embling CB, Hosegood PJ, Russell DJF (2016) Navigating uncertain waters: a critical review of inferring foraging behaviour from location and dive data in pinnipeds. Mov Ecol 4:25

Christensen Dalsgaard S, May R, Lorentsen SH (2018) Taking a trip to the shelf: behavioral decisions are mediated by the proximity to foraging habitats in the black legged kittiwake. Ecol Evol 8:866-878

Coles W, Musick JA, Price AH (2000) Satellite sea surface temperature analysis and correlation with sea turtle distribution off North Carolina. Copeia 2000:551-554 
Dellinger T, Davenport J, Wirtz P (1997) Comparisons of social structure of Columbus crabs living on loggerhead sea turtles and inanimate flotsam. J Mar Biol Assoc UK 77:185-194

Eckert SA, Moore JE, Dunn DC, van Buiten RS, Eckert KL, Halpin PN (2008) Modeling loggerhead turtle movement in the Mediterranean: importance of body size and oceanography. Ecol Appl 18:290-308

Estes JA, Terborgh J, Brashares JS, Power ME and others (2011) Trophic downgrading of planet earth. Science 333:301-306

Estes JA, Heithaus M, McCauley DJ, Rasher DB, Worm B (2016) Megafaunal impacts on structure and function of ocean ecosystems. Annu Rev Environ Resour 41:83-116

Fauchald P (1999) Foraging in a hierarchical patch system. Am Nat 153:603-613

Fauchald P, Tveraa T (2003) Using first-passage time in the analysis of area-restricted search and habitat selection. Ecology 84:282-288

Fauchald P, Tveraa T (2006) Hierarchical patch dynamics and animal movement pattern. Oecologia 149:383-395

Felger RS, Cliffton K, Regal PJ (1976) Winter dormancy in sea turtles: independent discovery and exploitation in the Gulf of California by two local cultures. Science 191:283-285

Freitas C, Kovacs KM, Lydersen C, Ims RA (2008a) A novel method for quantifying habitat selection and predicting habitat use. J Appl Ecol 45:1213-1220

* Freitas C, Lydersen C, Fedak MA, Kovacs KM (2008b) A simple new algorithm to filter marine mammal Argos locations. Mar Mamm Sci 24:315-325

Frick MG, Williams KL, Bolten AB, Bjorndal KA, Martins HR (2009) Foraging ecology of oceanic-stage loggerhead turtles Caretta caretta. Endang Species Res 9:91-97

Gaube P, Barceló C, McGillicuddy DJ Jr, Domingo A and others (2017) The use of mesoscale eddies by juvenile loggerhead sea turtles (Caretta caretta) in the southwestern Atlantic. PLOS ONE 12:e0172839

Hays GC, Bastian T, Doyle TK, Fossette S and others (2012) High activity and Lévy searches: jellyfish can search the water column like fish. Proc R Soc B 279:465-473

Hochscheid S, Bentivegna F, Hays GC (2005) First records of dive durations for a hibernating sea turtle. Biol Lett 1: 82-86

Hochscheid S, Bentivegna F, Bradai MN, Hays GC (2007) Overwintering behaviour in sea turtles: dormancy is optional. Mar Ecol Prog Ser 340:287-298

*Howell EA, Dutton PH, Polovina JJ, Bailey H, Parker DM, Balazs GH (2010) Oceanographic influences on the dive behavior of juvenile loggerhead turtles (Caretta caretta) in the North Pacific Ocean. Mar Biol 157:1011-1026

*Humphries NE, Queiroz N, Dyer JR, Pade NG and others (2010) Environmental context explains Lévy and Brownian movement patterns of marine predators. Nature 465: 1066-1069

* Humphries NE, Weimerskirch H, Queiroz N, Southall EJ, Sims DW (2012) Foraging success of biological Lévy flights recorded in situ. Proc Natl Acad Sci USA 109: 7169-7174

Johnson DH (1980) The comparison of usage and availability measurements for evaluating resource preference. Ecology 61:65-71

Kareiva P, Odell G (1987) Swarms of predators exhibit 'preytaxis' if individual predators use area-restricted search. Am Nat 130:233-270

Kobayashi DR, Polovina JJ, Parker DM, Kamezaki N and oth- ers (2008) Pelagic habitat characterization of loggerhead sea turtles, Caretta caretta, in the North Pacific Ocean (1997-2006): insights from satellite tag tracking and remotely sensed data. J Exp Mar Biol Ecol 356:96-114

* LaCasella EL, Epperly SP, Jensen MP, Stokes L, Dutton PH (2013) Genetic stock composition of loggerhead turtles Caretta caretta bycaught in the pelagic waters of the North Atlantic. Endang Species Res 22:73-84

KLohmann KJ (2007) Sea turtles: navigating with magnetism. Curr Biol 17:R102-R104

Mansfield KL (2006) Sources of mortality, movements and behavior of sea turtles in Virginia. PhD thesis, The College of William and Mary, Williamsburg, VA

Mansfield KL, Putman NF (2013) Oceanic habits and habitats - Caretta caretta. In: Wyneken J, Lohmann KJ, Musick JA (eds) Biology of sea turtles, Vol 3. CRC Press, Boca Raton, FL, p 189-210

Mansfield KL, Saba VS, Keinath JA, Musick JA (2009) Satellite tracking reveals a dichotomy in migration strategies among juvenile loggerhead turtles in the Northwest Atlantic. Mar Biol 156:2555-2570

Mansfield KL, Wyneken J, Porter WP, Luo J (2014) First satellite tracks of neonate sea turtles redefine the 'lost years' oceanic niche. Proc R Soc B 281:20133039

Mansfield KL, Mendilaharsu ML, Putman NF, dei Marcovaldi MAG and others (2017) First satellite tracks of South Atlantic sea turtle 'lost years': seasonal variation in trans-equatorial movement. Proc R Soc B 284:20171730

McCarthy AL, Heppell S, Royer F, Freitas C, Dellinger T (2010) Identification of likely foraging habitat of pelagic loggerhead sea turtles (Caretta caretta) in the North Atlantic through analysis of telemetry track sinuosity. Prog Oceanogr 86:224-231

McClellan CM, Read AJ (2007) Complexity and variation in loggerhead sea turtle life history. Biol Lett 3:592-594

* Monzón-Argüello C, Rico C, Carreras C, Calabuig P, Marco A, López-Jurado LF (2009) Variation in spatial distribution of juvenile loggerhead turtles in the eastern Atlantic and western Mediterranean Sea. J Exp Mar Biol Ecol 373:79-86

Morato T, Hoyle SD, Allain V, Nicol SJ (2010) Seamounts are hotspots of pelagic biodiversity in the open ocean. Proc Natl Acad Sci USA 107:9707-9711

Morris DW (1987) Ecological scale and habitat use. Ecology 68:362-369

*Myers RA, Baum JK, Shepherd TD, Powers SP, Peterson CH (2007) Cascading effects of the loss of apex predatory sharks from a coastal ocean. Science 315:1846-1850

* Nakagawa S, Schielzeth H (2013) A general and simple method for obtaining $\mathrm{R}^{2}$ from generalized linear mixedeffects models. Methods Ecol Evol 4:133-142

Nogueira Júnior M, Brandini FP, Codina JCU (2015) Diel vertical dynamics of gelatinous zooplankton (Cnidaria, Ctenophora and Thaliacea) in a subtropical stratified ecosystem (South Brazilian Bight). PLOS ONE 10:e0144161

Pankratz VS, de Andrade M, Therneau TM (2005) Randomeffects Cox proportional hazards model: general variance components methods for time-to-event data. Genet Epidemiol 28:97-109

Parker DM, Cooke WJ, Balazs GH (2005) Diet of oceanic loggerhead sea turtles (Caretta caretta) in the central North Pacific. Fish Bull 103:142-152

* Polovina JJ, Kobayashi DR, Parker DM, Seki MP, Balazs GH (2000) Turtles on the edge: movement of loggerhead turtles (Caretta caretta) along oceanic fronts, spanning 
longline fishing grounds in the central North Pacific, 1997-1998. Fish Oceanogr 9:71-82

Polovina JJ, Howell E, Parker DM, Balazs GH (2003) Divedepth distribution of loggerhead (Carretta carretta) and olive ridley (Lepidochelys olivacea) sea turtles in the central North Pacific: Might deep longline sets catch fewer turtles? Fish Bull 101:189-193

Polovina JJ, Balazs GH, Howell EA, Parker DM, Seki MP, Dutton PH (2004) Forage and migration habitat of loggerhead (Caretta caretta) and olive ridley (Lepidochelys olivacea) sea turtles in the central North Pacific Ocean. Fish Oceanogr 13:36-51

Putman NF, Mansfield KL (2015) Direct evidence of swimming demonstrates active dispersal in the sea turtle 'lost years'. Curr Biol 25:1221-1227

Putman NF, Verley P, Endres CS, Lohmann KJ (2015) Magnetic navigation behavior and the oceanic ecology of young loggerhead sea turtles. J Exp Biol 218:1044-1050

Putman NF, Lumpkin R, Sacco AE, Mansfield KL (2016) Passive drift or active swimming in marine organisms? Proc R Soc B 283:20161689

R Core Team (2015) R: a language and environment for statistical computing. R Foundation for Statistical Computing, Vienna

Sakamoto W, Naito Y, Uchida I, Kureha K (1990) Circadian rhythm on diving motion of the loggerhead turtle Caretta caretta during inter-nesting and its fluctuations induced by the oceanic environmental events. Bull Jpn Soc Sci Fish 56:263-272

Sapsford CW, van der Riet M (1979) Uptake of solar radiation by the sea turtle, Caretta caretta, during voluntary surface basking. Comp Biochem Physiol Part A Physiol 63:471-474

Scales KL, Miller PI, Varo-Cruz N, Hodgson DJ, Hawkes LA, Godley BJ (2015) Oceanic loggerhead turtles Caretta caretta associate with thermal fronts: evidence from the Canary Current Large Marine Ecosystem. Mar Ecol Prog Ser 519:195-207

Scott R, Biastoch A, Roder C, Stiebens VA, Eizaguirre C (2014) Nano-tags for neonates and ocean-mediated swimming behaviours linked to rapid dispersal of hatchling sea turtles. Proc R Soc B 281:20141209

Senft RL, Coughenour MB, Bailey DW, Rittenhouse LR, Sala OE, Swift DM (1987) Large herbivore foraging and ecological hierarchies. Bioscience 37:789-799

Shillinger GL, Swithenbank AM, Bailey H, Bograd SJ and others (2011) Vertical and horizontal habitat preferences of post-nesting leatherback turtles in the South Pacific Ocean. Mar Ecol Prog Ser 422:275-289

Editorial responsibility: Graeme Hays, Burwood, Victoria, Australia
Sims DW, Southall EJ, Humphries NE, Hays GC and others (2008) Scaling laws of marine predator search behaviour. Nature 451:1098-1102

* Sims DW, Humphries NE, Bradford RW, Bruce BD (2012) Lévy flight and Brownian search patterns of a free-ranging predator reflect different prey field characteristics. J Anim Ecol 81:432-442

Sommerfeld J, Kato A, Ropert-Coudert Y, Garthe S, Hindell MA (2013) Foraging parameters influencing the detection and interpretation of area-restricted search behaviour in marine predators: a case study with the masked booby. PLOS ONE 8:e63742

Southwood AL, Reina RD, Jones VS, Jones DR (2003) Seasonal diving patterns and body temperatures of juvenile green turtles at Heron Island, Australia. Can J Zool 81: 1014-1024

* Storch S, Hays GC, Hillis-Starr Z, Wilson RP (2006) The behaviour of a hawksbill turtle data-logged during the passage of hurricane Georges through the Caribbean. Mar Freshw Behav Physiol 39:307-313

Tew Kai E, Rossi V, Sudre J, Weimerskirch H and others (2009) Top marine predators track Lagrangian coherent structures. Proc Natl Acad Sci USA 106:8245-8250

* Thomson JA, Cooper AB, Burkholder DA, Heithaus MR, Dill LM (2012) Heterogeneous patterns of availability for detection during visual surveys: spatiotemporal variation in sea turtle dive-surfacing behaviour on a feeding ground. Methods Ecol Evol 3:378-387

Varo-Cruz N, Bermejo JA, Calabuig P, Cejudo D and others (2016) New findings about the spatial and temporal use of the Eastern Atlantic Ocean by large juvenile loggerhead turtles. Divers Distrib 22:481-492

*Viswanathan GM, Raposo EP, da Luz MGE (2008) Lévy flights and superdiffusion in the context of biological encounters and random searches. Phys Life Rev 5: $133-150$

White M, Bashmachnikov I, Arístegui J, Martins A (2008) Physical processes and seamount productivity. In: Pitcher TJ, Morato T, Hart PJB, Clark MR, Haggan N, Santos RS (eds) Seamounts: ecology, fisheries \& conservation. Blackwell Publishing, Oxford, p 65-84

*Wilson RP, Griffiths IW, Legg PA, Friswell MI and others (2013) Turn costs change the value of animal search paths. Ecol Lett 16:1145-1150

*Worm B, Tittensor DP (2011) Range contraction in large pelagic predators. Proc Natl Acad Sci USA 108: 11942-11947

Zuur AF, Ieno EN, Smith GM (2007) Analysing ecological data. Springer, New York, NY

Submitted: November 21, 2017; Accepted: March 27, 2018 Proofs received from author(s): April 25, 2018 